\section{Juicio por la Verdad en Mar del Plata, Argentina. Sobre el concepto de justicia en el relato de un testimonio}

Truth Trial in Mar del Plata, Argentina. About the notion of justice in the account of a testimony

\section{Estefanía Dı Meglio*}

\section{Resumen}

En el presente trabajo se elabora un análisis de un testimonio en el Juicio por la Verdad en la ciudad de Mar del Plata (provincia de Buenos Aires), juicio llevado con motivo de la última dictadura en Argentina. La declaración tiene lugar en el año 2001, época en la que todavía la memoria, verdad y justicia son cuestiones que se buscan desde posturas marginales frente al

\footnotetext{
Prof. y Lic. en Letras. Tesista de la Maestría en Letras Hispánicas y el Doctorado en Letras. Universidad Nacional de Mar del PlataCentro de Letras Hispanoamericanas - CONICET.

Dirección postal: Lavalle 4358, Mar del Plata, CP: 7600, Prov. de Buenos Aires, Argentina.

Correo electrónico: estefaniadimeglio@gmail.com
}

olvido, el silencio y la impunidad que propugnan las políticas oficiales. La hipótesis de trabajo radica en que el testimonio constituye un espacio simbólico de cierta reparación ante a los hechos vividos, a través de la elaboración de las ideas de justicia que tiene el testigo. En este sentido, el testimonio se convierte también en metatexto que reflexiona, en su propio interior, sobre cuestiones atinentes a los juicios y la justicia en general respecto del pasado traumático.

Palabras clave: Dictadura, Juicios por la Verdad, justicia, testimonio, reparación.

\begin{abstract}
In this article, an analysis of a testimony from the Truth Trial of Mar del Plata is developed. This trial was carried out after the latest Argentina's dictatorship (1976-1983). The testimony took place in 2001, period during which the so called "impunity laws" were still in force. In that period truth and justice were matters followed by alternative positions facing oblivion, silence and impunity, imposed by official policies. The hypothesis of this research lies in the fact that testimony becomes a symbolic space for redress in relation to the experienced. Reparation is possible thanks to the possibility of telling the story and own experience, so who gives testimony can formulate his or her own ideas of justice. Testimony also becomes a meta-text that reflects, in its own interior, on questions pertaining to trials and justice regarding the traumatic past.
\end{abstract}

Key words: Dictatorship, Truth Trial, justice, testimony, redress. 
El peso de los muertos hace girar la tierra de noche y de día (...)

Cuando sean más los muertos que los vivos, la noche será eterna, no tendrá fin. Miguel Ángel Asturias, El Señor Presidente

El presente trabajo se centrará en la figura del testimonio de una de las audiencias en el Juicio por la Verdad en Mar del Plata, ${ }^{1}$ juicio llevado a cabo para reconstruir la verdad sobre lo sucedido durante la última dictadura en Argentina (1976-1983), pero sin fines punitivos sobre los culpables. Se trata de Alfredo Battaglia, un abogado laborista perseguido por el último régimen castrense en el mencionado país. Se analizarán las formas en las que aparece el testigo-víctima y las representaciones que adquieren las nociones y conceptos de justicia en el interior del relato del propio testimonio. Todo lo que, en última instancia, permite dimensionar el juicio como un espacio material y simbólico en el cual el sujeto que testimonia encuentra el lugar vedado en otros ámbitos de lo social, con lo que el acto del juicio se convierte en una forma de reparación. Para ello, se tomará el ejemplo particular de Battaglia a modo de estudio de caso. La hipótesis a sostener para este caso particular, entonces, puede presentarse en los siguientes términos: el espacio del testimonio en el Juicio por la Verdad instala un lugar donde quien testimonia no solamente elabora el relato de los hechos de su experiencia singular vivida durante la dictadura y lo sucedido en el plano meramente factual, sino que se presenta también como sitio donde el hablante puede esbozar sus ideas sobre una dimensión más amplia que la de

Parte de la transcripción de las audiencias del Juicio por la Verdad en Mar del Plata se encuentra disponible en la página web de la Agremiación Docente Universitaria Marplatense (ADUM). El enlace es el siguiente: http://www.adum.org.ar/?cat=15 los acontecimientos, en la que elabora e ingresa una especie de metadiscurso a partir del cual se proyectan sus reflexiones sobre su propio testimonio y las ideas de justicia formuladas al exterior del discurso testimonial. Es decir que no solo desde el juicio como acto social, sino por medio del contenido y el relato que tiene lugar en ese juicio, se esbozan imágenes de justicia. Simultáneamente, este texto (el testimonio) permite hablar de un contexto. Los Juicios por la Verdad reconstruyen la noción sobre lo que se entiende por tal justicia en el presente y en un futuro. En este sentido el testimonio es, a la vez que instancia jurídica, documento sobre sus propios modos de construcción. La propuesta de trabajo se basa en un análisis lingüístico y discursivo del texto que constituye dicho testimonio, análisis que contempla las operatorias discursivas que dan cuenta del testimonio como espacio textual y simbólico reparador.

\section{Introducción: años de silencio y olvido}

El silencio característico de todo régimen de facto impuesto por la última dictadura en Argentina se extendió sobre la postdictadura. El acallamiento de toda voz disidente y contraria durante el gobierno militar tuvo su correlato en el silenciamiento de lo sucedido, bajo el inicial pacto de silencio de los represores en un primer momento y en el manto de silencio tendido por sucesivos gobiernos democráticos, en una segunda instancia. Estuvieron amparados muchas veces en el irrisorio argumento del olvido de los hechos en pos de la reconciliación ${ }^{2}$

El concepto reconciliación es empleado desde la inmediata postdictadura, asociado con la idea de pacificación pero con la estrategia subyacente de sepultar el pasado en el silencio y el olvido. 
y la reconstrucción democrática, ${ }^{3}$ argumento que rozó los extremos de la radicalización del olvido en intentos de destrucción de lugares que constituían pruebas materiales fundamentales del horror. ${ }^{4}$ Las décadas de impunidad dejan al margen el relato de quienes retornaron de esa lógica paralela -siniestra y ominosa del mundo de los represores y la tortura- a la realidad corriente (LaCapra 2006: 161-162).

Los perseguidos por el régimen sufrieron el silenciamiento comenzando por la censura de sus discursos hasta llegar a ser objeto, en muchos casos, del objetivo final de la persecución de los represores: la eliminación y desaparición del cuerpo. El "por algo será" reproducido por la sociedad civil en dictadura se resignificó en la postdictadura, imprimiéndose en los sobrevivientes como un sello que los estigmatizaba (Jelin 2010: 242). ${ }^{5}$

Nicole Louraux explica que "después de la derrota militar de Atenas y de la oligarquía de los Treinta, la prohibición de recordar las desgracias sella la reconciliación democrática", a la que se denomina "amnistía modelo -paradigma de todas aquellas que conocerá la historia occidental” (en Yerushalmi 1989: 30).

4 Como propuso hacerlo el entonces presidente Carlos Saúl Menem (ejerció dos mandatos presidenciales consecutivos, de 1989 a 1999) con el predio de la Ex ESMA (Escuela Superior de Mecánica de la Armada), la cual funcionó como uno de los más de seiscientos centros clandestinos de detención y tortura durante la dictadura. Menem pretendía la demolición de los edificios para su conversión en un "parque de la reconciliación", en 1998 (cfr. Crenzel 2010: 94 y 132).

5 Mientras tenía lugar el régimen castrense en Argentina, parte de la sociedad fue cómplice desde lo discursivo de los secuestros y desapariciones, complicidad que se expresaba por medio de enunciados como el "por algo será", referido a la gente que "se llevaban", es decir, a quienes desaparecían. El igualmente siniestro "algo habrán hecho" ["para que se los llevaran"] era una expresión también escuchada durante (y después de) la dictadura (Jelin en Crenzel 2010: 242). La lógica que reproducía la perversión de la frase una vez finalizado el régimen militar se basaba en el razonamiento que llevaba a concluir que "algo habrán hecho" para sobrevivir y salvarse del destino que le tocó al resto de los secuestrados que no sobrevivieron. Ese "algo" aludía a la colaboración con el régimen. A propósito del "tema del traidor y del héroe" (usando la frase que da título al cuento de Borges),
Se trataba, además, de una sociedad que no se hallaba preparada para la escucha de acontecimientos fundados en el mismo seno del horror y lo traumático: "no quiere saber lo que los desaparecidos tienen para contar" (Vezzetti 2002: 181; Pollak 2006: 24). ${ }^{6}$ "Hay testigos que no encuentran nunca la audiencia capaz de escucharlos y de oírlos" (Ricoeur 2003: 217), sentencia Paul Ricoeur. No es asunto menor el que no haya un espacio habilitado para la escucha, en tanto que se carece de interlocutores dispuestos a ser receptores del relato. Beatriz Sarlo lo formula en los siguientes términos:

En este punto, es indudable que fueron las organizaciones de derechos humanos las que, desde los rasgos novedosos de su práctica, contestaron a esta política de olvido con una reivindicación de la memoria. Sin embargo, no toda la sociedad podía escuchar su discurso, especialmente en momentos en que esa escucha era físicamente más peligrosa que el olvido (Sarlo 1987: 33).

Por su parte, más adelante en el tiempo, Elizabeth Jelin esboza:

Hay otra lógica del silencio. Para relatar sufrimientos, es necesario encontrar del otro lado la voluntad de

Daniel Badenes y Lucas Miguel aseveran que "la consigna todos los sobrevivientes son traidores, todos los desaparecidos son héroes -repetida en algunos ámbitos militantes- no abarca ni la complejidad ni la dramaticidad de la vida y la muerte en los campos de concentración y exterminio de la dictadura" (2007: 9). (Énfasis en el original). Hugo Vezzetti también trabaja este aspecto en su libro Sobre la violencia revolucionaria (Vezzetti 2009: 143).

6 Como lo demarca Jorge Semprún, sobreviviente del genocidio nazi, a menudo el problema no estriba tanto en la dificultad de hablar sobre el horror, sino en encontrar un interlocutor dispuesto a escuchar ese trauma: "No es ése el problema -exclama otro enseguida-. El verdadero problema no estriba en contar, cualesquiera que fueren las dificultades. Sino en escuchar... ¿Estarán dispuestos a escuchar nuestras historias, incluso si las contamos bien?" (Semprún 2004: 140). Este mismo temor manifiesta otro sobreviviente del horror del genocidio, Primo Levi: "Una cosa así había soñado yo, todos la habíamos soñado, en las noches de Auschwitz: hablar y no ser escuchados, encontrar la libertad y estar solos" (Levi 2006: 82). 
escuchar (Laub, 1992; Pollak, 1990). Hay coyunturas políticas de transición -como en Chile a fines de los ochenta, o en Francia de la posguerra- en que la voluntad de reconstrucción es vivida como contradictoria con mensajes ligados a horrores del pasado. En el plano de las memorias individuales, el temor a ser incomprendido también lleva a silencios. Encontrar a otros con capacidad de escuchar es central en el proceso de quebrar silencios (Jelin 2004: 15)

El silencio posee entonces diferentes enunciadores, con diversos motivos y se reviste de variadas significaciones, pero en casi la totalidad de los casos se da como consecuencia de la imposición del olvido. ${ }^{7}$ Con los Juicios por la Verdad, en cambio, el testigo-víctima encontrará un espacio de habilitación de la escucha, en el que parte del sistema judicial y de la sociedad se erigen como interlocutores válidos que legitiman tanto la posibilidad del relato del horror como de la reconstrucción de una verdad y la recuperación de una(s) historia(s).

Retomando el silencio impuesto, cabe señalar a los represores como los primeros que intentaron borrar todo registro de los crímenes perpetrados imponiendo primero el silencio en una sociedad víctima (y con cierta responsabilidad civil al mismo tiempo) y declarándose impunes al finalizar la dictadura mediante la denominada "Ley de Pacificación Nacional”, una autoamnistía que los hacía inmunes a todo castigo y por la que

\footnotetext{
Muy pocas voces pudieron modularse en contra del régimen. $\mathrm{O}$, mejor dicho, no era fácil que se escuchara la disidencia en el seno del terror. Las organizaciones de derechos humanos, surgidas antes y durante la dictadura, fueron una de aquellas voces que pudieron articular la denuncia de lo que estaba sucediendo. Asimismo, diversas manifestaciones de la cultura se pronunciaron en contra del régimen: la música, el teatro, la literatura, las artes plásticas son algunas de ellas. Una vez recuperada la democracia, estas disciplinas artísticas continúan con cuestiones como los pedidos de justicia, la elaboración del pasado reciente y la construcción de la memoria, con más o menos énfasis, dependiendo del contexto (de olvido, de silencio, de memoria) en el que se insertan en el campo de lo social.
}

exigían un compromiso, al gobierno sucesor, de no revisión sobre lo actuado. En otros términos, se trataba de una ley que entronizaba el silencio y el olvido del pasado. Pero más allá de eso, en 1985 serían juzgadas las cúpulas militares, aunque con concesiones de la recién recuperada y endeble democracia. ${ }^{8}$ Luego vendrían las denominadas Leyes de impunidad: Ley de Punto Final (1986), por la que no podrían presentarse más denuncias que inculparan a los militares, y Ley de Obediencia Debida (1987), por la cual los delitos cometidos por integrantes del sistema represivo que hubieran estado por debajo del grado de coronel no eran punibles. ${ }^{9}$ A esto siguieron, en 1989 y 1990, los indultos a los victimarios por parte del entonces presidente Menem, que hicieron que los militares caminaran por las mismas calles que las víctimas a las que habían privado de su libertad y torturado, por las mismas plazas en las que las madres pedían justicia por sus hijos desaparecidos y asesinados. Se consolidaron años de silencio, olvido e impunidad desde la oficialidad y los sucesivos gobiernos democráticos.

De igual manera, modos particulares de justicia surgían en el país: se trató de los Juicios por la Verdad (iniciados en 1998 en la ciudad de La Plata, capital de la Provincia de Buenos Aires), mediante los cuales no era posible condenar a los genocidas, pero sí podía reconstruirse una verdad jurídica sobre lo sucedido, al tiempo que

8 Este juicio, oral y público, tuvo lugar entre el 22 de abril y el 14 de agosto de 1985 y las sentencias fueron pronunciadas el 9 de diciembre del mismo año. En él se juzgaron a los miembros de las juntas militares que gobernaron Argentina entre 1976 y 1983

9 Esta medida respondió al hecho de que si bien Raúl Alfonsín, primer presidente electo luego de la dictadura, "asumió como necesario el juzgamiento de los crímenes cometidos para consolidar al sistema democrático reconstituido, también consideró prioritario limitar el alcance de los mismos en pos de mantener una relación armónica con el sector militar" (Lvovich y Bisquert 2008: 30). 
estas formas jurídicas significaban una de las torsiones de la memoria en medio del silencioolvido: sobrevivientes y familiares de víctimas podían hacer escuchar su palabra. Estos juicios fueron de capital importancia para aquellos posteriores, que finalmente sí lograron una condena a los represores (o al menos a parte de ellos). Es así que hacia los años 2000 se declara primero la nulidad de las denominadas Leyes de impunidad (año 2003) y luego su inconstitucionalidad (2005). ${ }^{10}$ Una nueva etapa se inaugura en la memoria y en la justicia en Argentina desde el gobierno de Néstor Kirchner (2003-2007) (continuada luego durante los dos mandatos de su esposa, Cristina Fernández, de 2007 a 2015): se articulan numerosas e importantes políticas de la memoria histórica, lo que constituirá un contexto particular para que los represores paguen (aunque ninguna condena pueda ser suficiente para pagar el horror) por sus crímenes, en un nuevo ciclo de justicia punitiva. ${ }^{11}$ De allí la importancia de analizar estos Juicios por la verdad, en tanto que sentaron precedentes que significaron un punto de partida sólido al momento de este nuevo ciclo de justicia penal. De igual manera,

10 Daniel Lvovich y Jaquelina Bisquert relevan al respecto: "El 14 de junio de 2005 la Corte Suprema de Justicia declaró la inconstitucionalidad de las leyes de Obediencia Debida y Punto Final, lo cual aceleró la presentación judicial de nuevas causas por violaciones a los derechos humanos y el tratamiento de las abiertas con anterioridad. A principios de 2006, dichas causas superaron el millar, y se sumaron a las casusas abiertas en el exterior" (Lvovich y Bisquert 2008, 85).

11 Resulta interesante destacar que más allá de la declaración de nulidad de estas leyes y de la reapertura de los juicios a los represores en Argentina, algunas ciudades continuaron con los Juicios por la Verdad. Esto demuestra la importancia que ellos han tenido y siguen teniendo en cuanto a la posibilidad que ofrecen a los testigo-víctimas para declarar y en lo que hace a aspectos centrales de la trama de lo social, como son la verdad histórica y jurídica y la memoria. En efecto, el propio juicio de Mar del Plata continuó hasta el año 2008, cuando el nuevo ciclo de justicia punitiva ya estaba reabierto. el tratamiento del tema del pasado reciente en general urge en un nuevo contexto que marca una nueva fase en la historia de la memoria en Argentina: concretamente, el actual gobierno de Mauricio Macri manifiesta una explícita voluntad de silencio y olvido, siendo que cuando trae el pasado traumático a sus discursos es únicamente para banalizarlo y como modo de provocación hacia los actores sociales que obtuvieron conquistas trascendentes ( $y$ ejemplares a nivel internacional) en el terreno de los derechos humanos. Se trata de un gobierno en el que desde el más alto mandatario se ironiza sobre el pasado como forma de desestimar los logros sobre aquel. Inclusive en la ciudad de Mar del Plata, el actual intendente (ex militar) pretende desmantelar acciones concretas que hacen a la construcción de la memoria colectiva (como por ejemplo la mención de sitios como plazas con nombres que refieren directamente a hechos del pasado reciente argentino). ${ }^{12}$

\section{Juicios por la Verdad}

Por oposición al silencio y a la marginalidad de ciertos relatos, que se desprenden como consecuencia de los años de impunidad, a fines de la década de los ' 90 y en el marco de la "explosión de la memoria" (Huyssen 2001) a nivel internacional y de un resurgir de la memoria en el plano local, surgen en Argentina los denominados Juicios por la Verdad (Varsky citada por Miguel 2006: 26; Crenzel 2010: 201). En estos años la memoria, aunque permanece confinada en el ámbito de lo alternativo en tanto que la oficialidad continúa ocluyendo el pasado

\footnotetext{
2 Los pronunciamientos del gobierno en cuanto al pasado reciente argentino trajeron aparejada como consecuencia la emergencia de discursos pro militares en la sociedad y que buscan desacreditar las conquistas en el terreno de la memoria.
} 
reciente, se reviste de impulsos renovados con motivo de la aparición de nuevas voces y agentes en la escena pública. De esta manera, aparecen en la escena pública represores que dan su relato sobre los crímenes perpetrados, como el ex capitán de Marina Adolfo Scilingo, quien habla sobre los vuelos de la muerte, ${ }^{13}$ o el ex general Martín Balza, que hace una autocrítica (siempre tendenciosa) sobre lo actuado. Asimismo, se asiste al origen de una agrupación que dará a conocer voces antes desconocidas sobre el período: se trata de H.I.J.O.S. (Hijos por la Identidad y la Justicia contra el Olvido y el Silencio). Por otra parte, los procesos judiciales a nivel internacional fueron centrales para dar origen a los Juicios por la Verdad: en marzo de 1996, el comienzo de un juicio en España por violaciones a los derechos humanos en Argentina "generó una demanda directa de información acerca de lo acontecido durante el terrorismo de Estado en la ciudad [de Mar del Plata] que dio inicio a un proceso de cooperación entre un grupo de integrantes de organismos de derechos humanos y sobrevivientes a fin de satisfacer esa demanda" (Andriotti Romanin 2013b, 238). ${ }^{14}$ Así como lo

13 En febrero de 1995, en entrevista con el periodista argentino Horacio Verbitsky, el ex capitán de Marina Adolfo Scilingo reconoce la existencia de los denominados vuelos de la muerte por los cuales muchos desaparecidos fueron arrojados con vida al río o al mar (la publicación llevará el título de El vuelo). Esta información ya era conocida hacía tiempo, pero recién con las declaraciones de Scilingo halla asidero en el relato que decide construir la sociedad. Esto muestra, en parte, la hipótesis esgrimida anteriormente según la cual en la inmediata postdictadura la sociedad no estaba preparada para la escucha de lo traumático.

14 El autor lo explica en los siguientes términos: "En este aspecto, asistimos a una versión del 'efecto boomerang' señalado por Keck y Sikking (1998) marcado por una compleja retroalimentación entre el proceso desarrollado en el tribunal español y la tarea de los organismos de derechos humanos en Mar del Plata: la demanda del tribunal internacional potenció la acción de los integrantes de los organismos en búsqueda de información que, a su vez, enviaban como prueba al proceso español y que, una vez presentada en el mismo, al ser difundida por los medios de postula Enzo Traverso para el caso de juicios relacionados con la Segunda Guerra Mundial, la emergencia de una memoria colectiva juega un papel preponderante en relación con la justicia:

Sería difícil comprender los juicios a Barbie, Touvier y Papon en Francia, el juicio a Priebke en Italia o incluso las tentativas de instrucción de un juicio a Pinochet, tanto en la sociedad civil de esos países y de la opinión pública mundial, sin relacionarlos con el surgimiento, en el seno de la sociedad civil de esos países y de la opinión pública mundial, de una memoria colectiva del fascismo, de las dictaduras y de la Shoah. Estos juicios fueron momentos de rememoración pública de la historia, en los que el pasado fue reconstruido y juzgado en una sala de tribunal (Traverso 2011: 71).

Más adelante reafirma la relación que él entiende fundamental entre memoria, justicia e historia:

La justicia fue, a lo largo de todo el siglo XX -al menos luego de Nuremberg o desde el caso Dreyfus- un momento importante en la formación de una conciencia histórica colectiva. La imbricación de la historia, de la memoria y de la justicia está en el centro de la vida colectiva. El historiador puede operar las distinciones necesarias pero no puede negar esta imbricación; debe asumirlas, con las contradicciones que se derivan de ella (Traverso 2011: 75).

Estos juicios tuvieron lugar en diferentes ciudades de Argentina (La Plata, Ciudad de Buenos Aires, Bahía Blanca, Córdoba, Rosario, Resistencia, Mendoza, Mar del Plata, Salta y San Salvador de Jujuy). Como se señaló, el primero de ellos comenzó en la ciudad de La Plata, en el mes de abril de 1998. Previamente, la Asamblea Permanente por los Derechos Humanos y algunos familiares de desaparecidos habían presentado un recurso de amparo ante la Cámara Federal de La Plata a los efectos de solicitar la averiguación de la verdad en relación con los crímenes cometidos durante

comunicación generaba nuevos efectos a nivel local, creando nuevas oportunidades para los organismos" (2013b: 70). 
la dictadura. La Cámara resolvió investigar el destino final de las personas y las circunstancias de su desaparición. ${ }^{15}$

Por su parte, el Juicio por la Verdad de Mar del Plata tuvo lugar entre diciembre del año 2000 y abril de 2008 en el Tribunal Oral Federal Número 1 , siendo el primero del país en realizarse fuera de una Cámara Federal. Impulsado por la Comisión del Juicio por la Verdad, integrada por organismos de derechos humanos, diversas instituciones públicas nacionales y municipales, sindicatos, partidos políticos y organizaciones sociales de la localidad (Andriotti Romanin 2010: 10). Las audiencias fueron el asidero de más de trescientos testigos. A partir de la información generada en el juico se iniciaron procesos penales contra civiles y militares involucrados en el Terrorismo de Estado. Como resultado de algunas de estas causas se realizaron los primeros juicios penales por delitos de lesa humanidad (Andriotti Romanin 2010: 11).

Ciertas particularidades dadas en el sistema jurídico internacional y algunas restricciones en el sistema jurídico argentino crearon un antecedente propicio a la celebración de este tipo de juicios (Andriotti Romanin 2010: 14). Hubo, en otros países (España, por ejemplo), procesos judiciales que buscaron investigar sobre la desaparición de personas en Argentina durante la última dictadura. De igual manera, diferentes organizaciones de derechos humanos

Para esta parte de reconstrucción de los orígenes del Juicio en Mar del Plata y para la primera parte del apartado "El testimonio" se toman los aportes de Enrique Andriotti Romanin y su tesis de doctorado titulada Las luchas por el sentido del pasado dictatorial en la ciudad feliz. Memoria(s) y política(s) en el Juicio por la Verdad de Mar del Plata (2010), disponible en: https://www.ungs.edu.ar/ wp-content/uploads/2012/06/Tesis_Andriotti_Romanin.pdf. El autor es especialista de referencia en los Juicios por la Verdad en la ciudad de Mar del Plata. efectuaron presentaciones ante diversas instancias supranacionales como la Corte Interamericana de Derechos Humanos (CIDH). La finalidad de tales apelaciones residía en poner en tela de juicio las denominadas Leyes de Impunidad (Andriotti Romanin 2010: 33).

Entonces, en medio de la impunidad propulsada por el oficialismo e instalada en la sociedad, tales juicios se constituyen como un espacio a partir del cual hacer frente al silencio y desde donde indagar sobre una cuestión dejada de lado por la justicia desde el Juicio a las Juntas en 1985 y las denominadas Leyes de impunidad: "Mediante estos juicios se procura restituir el derecho de los familiares a la verdad de lo ocurrido y el derecho a la información de la sociedad civil" (Memoria Abierta 2010: 125). A tal reconstrucción de la verdad subyace cierta dimensión de lo reparador, tanto para familiares y allegados de víctimas como para los sobrevivientes que han vuelto del horror. Elizabeth Lira sostiene:

La verdad judicial ha implicado reconstruir y confirmar los hechos como efectivamente sucedidos, identificando sus circunstancias y a sus protagonistas. En los procesos judiciales, esa verdad permite la tipificación de los crímenes y la sentencia según el grado de participación en los delitos. Lograr la verdad (conocer lo que ha sucedido) y hacer justicia (reconocer los derechos de las personas, sancionar a los responsables) contribuye a la reparación psicológica y moral de las víctimas, precisamente porque los hechos fueron negados, las víctimas fueron objeto de escarnio y estigmatización, además del agravio y de los daños y las pérdidas sufridas cuando ocurrieron los sucesos (Lira en Vinyes 2009: 69) (Énfasis en el original).

De igual manera, la reparación o, más precisamente la elaboración del trauma, se extiende a las generaciones posteriores:

El trauma psíquico sin elaboración tiene repercusiones -conscientes e inconscientes- sobre los descendientes. 
No se trata de una transmisión de síntomas, sino de una percepción del sufrimiento parental por el lado de las identificaciones, mecanismo fundamental en la construcción del psiquismo humano: en tanto reconocimiento del yo, y del otro (Miñarro y Morandi en Vinyes 2009: 458).

La necesidad imperiosa de juicio y condena (o "juicio y castigo", como reza la consigna), a los culpables es tan fuerte que el día 4 de mayo de 1995 (antes de los Juicios por la Verdad en Argentina), las Madres de Plaza de Mayo llevan a cabo un "Juicio ético y popular" en la Plaza que les da nombre (cfr. Asociación Madres de Plaza de Mayo), frente a la Casa de gobierno, el lugar que las vio nacer y que fue y sigue siendo, al día de hoy, el espacio físico público central de sus reclamos, denuncias y formas de memoria. Dicho juicio tuvo su réplica en la ciudad de La Plata el día 7 de junio del mismo año. Se trató, ante el imperio de la impunidad de los genocidas y la falta de justicia, de una escenificación de la situación de juicio, con la participación de diferentes actores sociales y, sobre todo, de la población que quisiera estar presente. Sin dudas, esta acción social está atravesada por una dimensión simbólica de lo reparador, por el carácter ritual que, como se verá más adelante, investirá luego a los Juicios por la Verdad en su condición de espacios simbólicos que brindan lugar a una verdad y una justicia vedadas por el oficialismo de entonces.

\subsection{Representaciones de justicia y democracia}

Los conceptos de verdad y justicia fueron disociados en los Juicios por la Verdad en Argentina, en tanto que tales instancias jurídicas no buscaban la punición judicial (al menos en lo inmediato) sino reconstruir la verdad sobre lo sucedido. Ruti Teitel señala la disociación de los términos de justicia y verdad en una ecuación que, ante la carencia de la primera, pone la verdad en un primer plano: "El modelo más destacado en esta fase es el que se conoce como el modelo restaurativo. En esta fase, el propósito principal de la justicia transicional fue construir una historia alternativa de los abusos del pasado. Emergió entonces una dicotomía entre verdad y justicia (Teitel 2003: 11)". ${ }^{16}$ No obstante, se torna necesario hacer una salvedad, en cuanto que tal disociación no implica que ambos conceptos sean excluyentes uno del otro, como sí podría de alguna manera pensarse, por ejemplo, en torno de los juicios en Sudáfrica, en los cuales se buscaba la verdad en detrimento de la justicia. En un plano material, y con la esperanza de que algún día los juzgamientos a los represores fueran posibles, buscaron sentar testimonios y pruebas para ello. Es en esta dirección que la idea de justicia no queda ajena, aunque en una primera instancia solo se hable de verdad. Por

16 En el mismo artículo el autor se refiere a las "comisiones de verdad": "Así, el paradigma de la fase II mayoritariamente evitó enjuiciamientos para, en cambio, concentrarse en un nuevo mecanismo institucional: las comisiones de verdad. Una comisión de verdad es un organismo oficial, habitualmente creado por un gobierno nacional para investigar, documentar y divulgar públicamente abusos a los derechos humanos en un país durante un período de tiempo específico. Si bien este nuevo mecanismo institucional fue usado por primera vez en la Argentina, este modelo investigativo es ahora asociado con la respuesta adoptada por la Sudáfrica post-Apartheid en los años '90. Desde entonces, se han propuesto o convocado comisiones de verdad y reconciliación de diversos tipos en todo el mundo y -frecuentemente- han generado un significativo apoyo internacional (...). Lo atrayente de este modelo es su capacidad para ofrecer una perspectiva histórica más amplia, en lugar de meros juicios para casos aislados. Las comisiones de verdad son preferidas donde el régimen predecesor hizo desaparecer personas u ocultó información sobre su política persecutoria, como fue el caso típico en Latinoamérica. En contraste, las comisiones de verdad han sido de poco interés en la Europa post-comunista, donde el uso de la historia por parte de los gobiernos fue en sí mismo una dimensión destructiva de la represión comunista. En consecuencia, en la Europa del Este, la respuesta crítica principal de los regímenes sucesores no fue crear historias oficiales, sino que garantizar el acceso a los archivos históricos" (Teitel 2003: 11). 
el contrario, de manera latente está presente tanto en los testimonios como en los juicios en los que ellos se enmarcan.

Resulta pertinente revisar las reflexiones teóricas sobre el tema postuladas por algunos autores, a los fines de mejor explicar ciertos rasgos. En su artículo "Decir la verdad, hacer justicia: Los juicios por la verdad en Argentina", Enrique Andriotti Romanin releva las especificidades de tales juicios y explica la relación que se establece entre verdad y justicia: "Si la opción de un intercambio de perdón por verdad era clave en las comisiones que seguían el modelo sudafricano, basado en el carácter 'curativo' del testimonio y en la noción de reconciliación como objetivo central, para los familiares y las víctimas del terrorismo de Estado en Argentina que impulsaron estos juicios esto no era una opción viable" (Andriotti Romanin 2013a: 1415). El autor advierte la potencial presencia de la justicia más allá de que los juicios fueran por la verdad, situada aquélla en una fase de transición:

Precisamente, el horizonte de la justicia penal retributiva estuvo presente desde un comienzo en esta modalidad de justicia transicional $y$, en cierto modo, estos juicios fueron entendidos por los familiares de las víctimas y sobrevivientes del terrorismo de estado como parte de una secuencia, de un eslabón de una cadena que debía terminar en un futuro con el castigo penal de los responsables de los delitos de lesa humanidad y crímenes durante la dictadura (Andriotti Romanin 2013a: 15)

Andriotti Romanin establece que "se trata, en definitiva, de procesos judiciales que 'implican medidas de transición a la justicia'" (Schapiro citado por Andriotti Romanin 2013a: 7). Destacan ciertas características de este tipo de juicios, asociadas a la noción misma de justicia. Hernán Schapiro enumera tales cualidades:
1) son una tribuna de libre expresión, a la que acceden personas que nunca antes habían tenido un marco institucional en el que contar su historia;

2) cumplen el importante rol de institucionalizar socialmente la verdad;

3) constituyen un sitio de permanente reclamo de justicia y una puerta abierta a la historia;

4) (...) constituyen verdaderas bases de datos, muchas veces inéditos, a las que acuden familiares de las víctimas y organismos de derechos humanos, así como otros entes oficiales (...);

5) se han transformado en una llama de memoria permanente encendida;

6) conforman un sitio apto para el señalamiento público de los responsables del terrorismo de estado que gozan de impunidad;

7) constituyen un reservorio de prueba útil para formular denuncias penales ante los jueces que no reconocen limitación legal alguna a su potestad jurisdiccional (Schapiro 2002: 399-400).

Asimismo, "da Silva Catela ha destacado su dimensión simbólica y jurídica al señalar que constituyen un lugar donde se consagra simbólicamente la búsqueda de la verdad y en los cuales se desarrolla la función legitimadora de asentamiento de antecedentes" (Andriotti Romanin 2013a: 7). Memoria Abierta (2010: 124) sitúa estos juicios como parte de "una estrategia instrumental que abrió nuevos caminos para la justicia y la memoria 'generando información que pudiera ser usada en otras causas o en la reapertura de otras iniciadas en la década de los años 80'” (Andriotti Romanin 2013a: 8). El juez Gabriel Cavallo subraya el mismo aspecto: "Los Juicios por la Verdad fueron la única alternativa para mantener alguna esperanza de reapertura de los juicios con persecución penal tal cual hoy 
los vemos en muchas jurisdicciones del país" (Miguel 2006: 17).

\section{El testimonio}

Estos juicios tan singulares, en los que la búsqueda inmediata no fue de justicia sino de verdad, presentaron rasgos específicos que los diferenciaron de la modalidad tradicional característica de los juicios penales. Andriotti Romanin explica una primera divergencia en cuanto a la constitución de las partes, sus roles y posturas adoptadas:

En primer lugar, a diferencia de otros juicios que se realizan en el fuero penal, en los cuales se observa un enfrentamiento entre partes (una que acusa y otra que debe defenderse), en este juicio no existía parte defensora. No obstante, los profesionales del derecho (los jueces, el fiscal, el secretario y los abogados) mantenían las formas y el trato entre estos replicaba todos los procedimientos del ritual jurídico. Sin embargo, al ser el objeto del mismo la búsqueda de la verdad, en el escenario judicial predominaba entre las partes intervinientes la cooperación antes que el conflicto. En la práctica, esto desdibujaba las funciones que desempeñaban los actores y que podían encontrarse en otros juicios. Aunque formalmente se mantenían las jerarquías y diferencias de rol entre los miembros del tribunal, los testimoniantes, el fiscal y los abogados de la querella, en distintas ocasiones estas se veían modificadas. Así, el fiscal, al no tener a quién acusar, adoptaba por momentos el rol de un abogado querellante más. Por otra parte, en algunas ocasiones los jueces abandonaban la distancia normalmente establecida con los testigos interesándose por su estado emocional y de salud (2010: 101).

Mientras que en el Juicio a las Juntas de 1985 la subjetividad de los declarantes era ostensiblemente dejada a un lado (véase nota 18) por parte de los magistrados, ahora, como señala Andriotti Romanin, son ellos mismos quienes se adentran en ella. En cuanto a este aspecto, emerge una característica de vital importancia en lo que hace a la presentación del testimonio. Así, el relato objetivo característico de los testimonios en los juicios penales, basado en la existencia de hechos empíricos pasibles de comprobación, cede lugar a la manifestación de sentimientos, emociones y afectos. El carácter inédito de los sucesos, por responder a la paraexperiencia del mundo concentracionario, sumado a la particularidad de estos juicios "sin justicia" es en parte el motivo de la lógica y el funcionamiento singulares del escenario judicial. En esta dirección, otro de los rasgos particulares de estos juicios es la relevancia que adquieren los testimonios, los cuales adquieren un lugar central. Su importancia está dada, en cierto grado, por jugar un papel central en la reconstrucción de una verdad sobre los crímenes que sistemáticamente ha sido velada, obliterada u ocultada por los perpetradores. "Por las características de clandestinidad y el ocultamiento masivo de los crímenes, en la Argentina, treinta años después, los testimonios son la prueba central de lo ocurrido" (Rousseaux 2009: 37). ${ }^{17}$ Como destaca Andriotti Romanin,

17 Jelin postula la verdad como un estadio anterior y necesario para luego administrar justicia. En el marco de la ausencia de datos e información por acción directa de los dictadores, se trata de establecer qué sucedió: "En un sentido muy general, toda demanda de justicia consiste en la exigencia de la restitución de un equilibrio dañado. En este sentido general, el ejercicio de justicia requiere que se tenga conciencia de la dimensión de un daño para saber cuál es la medida del esfuerzo a realizar para repararlo. La desaparición es efectivamente un daño. Un daño de una clase muy peculiar. Es conocido que uno de los mecanismos fundamentales de este dispositivo represivo ha sido ocultar sistemáticamente toda información cierta. La desaparición, concebida como daño, implica tanto el secuestro de un cuerpo como la sustracción de un saber. Hallamos aquí una de las particularidades del fenómeno del movimiento de derechos humanos: respondiendo a un daño incierto desarrolla entonces una demanda de justicia indeterminada. Todo lo que en principio puede decirse es que algo ha ocurrido, una de las primeras tareas del movimiento fue establecer, con algún grado de certeza, qué" (1995, 119). Frente a las versiones oficiales articuladas por los militares durante la dictadura, los Juicios por la Verdad emergen como discursividades desde las cuales se elabora, se da a conocer y se pretende investigar sobre una verdad ocultada por los perpetradores. 
(...) en el transcurso de las audiencias el relato de los testigos ocupaba el lugar central. Por ende, la indagación que realizaba el fiscal se centraba en preguntas regidas por un espíritu investigativo con el objetivo de ampliar el testimonio. La modalidad del juicio le otorgaba a los testigos un lugar preponderante en la sala: pasaban a declarar al centro de la misma, frente al tribunal y de espaldas al público y se explayaban contándole al tribunal todo lo que habían visto o vivido, así como también sus sensaciones e impresiones respecto a lo acontecido en los casos en cuestión (2010: 101-102).

Esta centralidad del relato en lo que hace al dispositivo del juicio viene a replicar la centralidad del testigo en cuanto a construcción de la verdad jurídica (así como de la memoria). Y a propósito de la declaración, surge también otra particularidad que la diferencia de juicios anteriores y que va a perpetuarse luego, en el nuevo ciclo de justicia retributiva abierto en 2005: las posibles incoherencias factuales y discursivas del testimonio, lejos de invalidarlo, están previstas en tanto que las condiciones de la experiencia relatada por los testigos se fundan en el mismo seno de lo traumático, de una vivencia que no ha sido inscripta en el registro de lo consciente. Así lo explica una de las psicólogas, integrante de un grupo de acompañamiento a testigos en el año 2009:

(...) el equipo de psicólogas trabajó básicamente en relación a la idea de que aquí el sujeto que habla está posicionado en un presente traumático cuyo proceso discursivo de evocación no responde a una cronología y modalidad esperada dentro de los procesos evocativos de la memoria normal. El sujeto habla desde un pasado que no ha sido inscripto, y desde un dolor que no deja de sentirse en el cuerpo, produciendo así un testimonio desordenado, confuso, anacrónico, marcado por lagunas amnésicas, valorando determinadas imágenes sobre otras, omitiendo datos, etc.". (Tejera citada en Duhalde et al. 2009: 71). ${ }^{18}$

18 En efecto, Slavoj Žižek señala: "Además hace falta una distinción entre verdad (factual) y veracidad: lo que hace del testimonio de una mujer violada (o de cualquier otra descripción de un trauma) algo veraz es su incoherencia factual, su confusión, su informalidad"
Las declaraciones de Alfredo Battaglia, el testimonio en cuestión, en febrero de 2001 en el marco del Juicio por la Verdad en Mar del Plata transitan cuestiones transversales a este tipo de juicios, como lo son la reconstrucción de la verdad y la búsqueda -y esperanza- de una justicia en el futuro.

Alfredo Nicolás Battaglia fue un abogado laboralista y dirigente del Partido Comunista Argentino que dedicó su carrera, hasta el final de sus días en 2012, a la defensa de los derechos de los trabajadores. ${ }^{19}$ Había sido candidato a intendente del partido de Dolores (provincia de Buenos Aires) por el comunismo, en 1958. A raíz de esto, fue secuestrado a las tres de la madrugada del día 25 de marzo de 1976 (tan solo unas horas después del Golpe de Estado) y llevado a diferentes centros clandestinos de detención, tortura y exterminio (CCDTyE) en diversas ciudades de Argentina. Todo esto, llevado a cabo por una dictadura que, como todas, no toleraba ninguna ideología opuesta -o tan solo ligeramente diferente- a la suya. Sin

(Žižek 2013: 12). En esta misma dirección es que cambiará la valoración de la prueba en los juicios posteriores. Anteriormente, en el Juicio a las Juntas "(...) se privilegió la construcción de pruebas jurídicas, a partir de testimonios, privilegiando, por ende, sólo los datos que pudieran servir para probar los crímenes, con lo cual todo lo que excediera tales datos, como la subjetividad del testigo, era descartado" (Lvovich y Bisquert, 2008: 39). Pero no sería razonable pretender que personas que estuvieron secuestradas y bajo amenazas constantes, con sus ojos vendados, sometidas a una deprivación sensorial que les hacía perder las nociones de tiempo y espacio, víctimas de torturas físicas y psicológicas, fueran capaces de reconstruir la experiencia de un modo totalmente lógico y acabado, como si la hubieran percibido en otras condiciones. De allí el cambio en el valor de la prueba en los posteriores juicios.

19 En diciembre de 2012 fue declarado "Ciudadano Ejemplar" pos mortem por el Honorable Concejo Deliberante del Partido de General Pueyrredon (al que pertenece la ciudad de Mar del Plata), "por su defensa y militancia de los derechos fundamentales reconocidos por la Constitución Nacional y trayectoria inspiradora y modelo para la sociedad" (fuente: Boletín digital del Honorable Concejo Deliberante). 
dudas, para un gobierno cuyo plan económico se basaba en el neoliberalismo y con ello en la liberalización financiera y la desregulación laboral, cualquier forma de defensa de los trabajadores significaba un modo inexorable de oponerse al régimen. Por ello, este último dimensionó a tales profesionales como un claro "enemigo" suyo. Durante la llamada Noche de las Corbatas (nombre dado por los propios represores $)^{20}$ que tuvo lugar entre el 6 y 7 de julio de 1977, seis abogados laboralistas fueron secuestrados en la ciudad costera de Mar del Plata por un grupo del Ejército Argentino. Los profesionales fueron torturados en reiteradas oportunidades (torturas físicas y psicológicas), conforme a las prácticas del genocidio que supuso la última dictadura en Argentina. Algunos de ellos fueron desaparecidos por el régimen. Éste es uno de los casos del Juicio por la Verdad en Mar del Plata. Los testimonios de sobrevivientesytestigossecundarios permitieron reconstruir los crímenes perpetrados por los secuestradores, torturadores y genocidas.

El día de su audiencia, inmediatamente después de presentarse, lo primero que hace Alfredo Battaglia es referirse a la importancia de la posibilidad de testimoniar, de manera tal que esto contrasta con el silencio y la imposibilidad del relato de los hechos a los que se oponen y enfrentan estos juicios. Así, y aunque solo en cierta medida, la justicia comienza en el momento en el que se restituye a las víctimas el

En el libro La Noche de las Corbatas (2016), Felipe Celesia y Pablo Waisberg reconstruyen el momento de esta denominación: "El represor circulaba entre los cinco abogados con lentitud, marcando cada paso con los tacos. - ¿Qué es esto? — preguntaba, hacía una pausa breve y respondía: -Esta es la Noche de las Corbatas. A sus pies estaban las víctimas: encapuchadas, torturadas, temerosas y confundidas. - ¿Qué es esto? -insistía-. Esta es la Noche de las Corbatas, pero resulta que ahora los que administramos justicia somos nosotros" (2016, p. 11). derecho a la palabra, esto es, la posibilidad de testimoniar. En segundo lugar, deriva de ello la búsqueda de la verdad y la coloca en un primer plano de importancia, destacando la finalidad de su testimonio:

En primer lugar, no puedo dejar de manifestar, como lo ha manifestado este Tribunal, una expresión personal que es la de sentir una satisfacción de poder declarar en Mar del Plata y acerca de hechos que he revivido, que conozco y de lo que he sentido durante ese momento. Se trata de conocer realmente la verdad o parte de la verdad en esta denuncia que han formulado organizaciones defensoras de los derechos humanos, que no es ninguna novedad, han sido desde el principio de este proceso los que llevaron adelante las madres, los abuelos, los familiares, la denuncia permanente acerca de las atrocidades cometidas durante el período, por lo menos desde el '76 hasta el '83. ${ }^{21}$ Este verdadero genocidio que ocurrió en Argentina -porque es así- ya veremos que realmente es un genocidio (Audiencia, 1) ${ }^{22}$.

Ésta y otras ideas sobre la justicia son tematizadas, referidas $\mathrm{o}$ tan solo aludidas en la declaración de Battaglia, generando representaciones en el interior del testimonio que exceden y a la vez se corresponden con la idea de justicia que implica la instancia del Juicio por la Verdad. Acaso para el momento fuera únicamente una esperanza, pero lo cierto es que, en efecto, el declarante manifiesta su convicción acerca del juzgamiento futuro, en correspondencia con la idea de justicia que, como se vio anteriormente, subyace a estos juicios:

Algún día, yo no tengo la menor duda que esos van a ser juzgados o que van a cumplir algo de eso, porque hasta ahora, hasta ellos se creyeron impunes después del Punto

21 En realidad, y como se verá en lo posterior, el juicio extiende los límites temporales a las antesalas políticas de la dictadura (Audiencia; Andriotti Romanin 2013b: 211).

22 Audiencia de Juicio por la Verdad (05-02-2001). Mar del Plata. Testimonio de Alfredo Battaglia. Cada vez que se citen las palabras de dicho testimonio aparecerán seguidas del indicador "(Audiencia, número de página)". 
Final, después de la Obediencia Debida y después del indulto. Hasta ellos se creyeron que iban a ser impunes y hoy, las noticias de ayer, que dan amplia alegría a quienes tenemos todavía algunas utopías y queremos que el mundo se modifique para bien, es una alegría que el poder político de México haya autorizado la extradición de un torturador como [Ricardo Miguel] Cavallo, para ser juzgado por las autoridades de la justicia española (Audiencia, 36)

El anterior fragmento instala la idea de posibilidad de justicia retributiva en un futuro. El testimonio delimita ciertas zonas temporales a propósito de la justicia, dadas en parte por el contexto político en el que se sitúan. Es decir, es posible diferenciar sus diversas etapas en una temporalidad que abarca las imágenes, representaciones y formas de la justicia durante el pasado dictatorial y luego la transición democrática, por un lado, durante el presente de los Juicios por la Verdad, por otro y, por último, la justicia retributiva en un futuro muchas veces esperable pero incierto al fin (para ese entonces). En otro aspecto, determinadas referencias como la mención de la militancia política del sujeto o la pregunta por ciertos nombres por parte de los abogados y fiscales anclan el testimonio en un contexto específico, por oposición a otros. Así, una de las primeras cuestiones que menciona Battaglia, recién iniciada su declaración, es su militancia política: "mi profesión es abogado y he sido militante de un partido político desde hace muchos años, el Partido Comunista Argentino, con el cual me he identificado permanentemente, que hace más de cincuenta años que soy afiliado" (Audiencia, 1). ${ }^{23}$ La referencia a la militancia era algo casi impensado en el Juicio que tuvo lugar en 1985. En efecto, "durante el juicio a las Juntas, según el relato de los testigos citados a declarar, la

Emilio Crenzel analiza las diferentes representaciones, a lo largo del tiempo, de los perseguidos políticos y los desaparecidos (2010: 21 y ss). fiscalía les advirtió que no hicieran mención a su militancia política" (Varsky 2011: 65; Andriotti Romanin 2013b: 102). ${ }^{24}$ Esto encuentra su motivación en dos aspectos principales: por una parte, la democracia reciente era vista como endeble y no existían garantías para su permanencia; por otro lado, circulaba la idea de que el ejercicio de la justicia sería más efectivo con la despolitización de las víctimas -lo que, entre otros motivos, dio lugar a la imagen de la "víctima inocente" (Crenzel 2008: 118). Pueden explicarse las causas de la omisión de la referencia a la militancia en que:

\begin{abstract}
Esto probablemente haya tenido que ver, por un lado, con el momento histórico: recién comenzaba la democracia, no había aún prueba de sustentabilidad en el tiempo, y la amenaza militar se presentaba como una posibilidad. Por otro lado, y más en relación con la estrategia de la acusación en el juicio, probablemente tuvo que ver con la utilización de la defensa de la "teoría de los dos demonios". En ese sentido, la referencia a la militancia política podría haber sido objeto de ataque por parte de la defensa y de alguna manera se trató de evitar, aunque con un claro ocultamiento de la identidad de las víctimas (Varsky 2011: 65).
\end{abstract}

Puede añadirse a lo anterior el argumento esgrimido por Michael Pollak: “(...) En este caso de 'crimen contra la humanidad', ${ }^{25}$ todo

$24 \quad$ Leonardo Filippini subraya lo siguiente: "Hoy (...) la reivindicación de la militancia política está fuertemente expresada en el pedido de calificación de los hechos como genocidio" (Filippini 2011: 43, n. 13). Si bien su aserción está contextualizada alrededor del año 2011, resulta interesante para poner en correlación -aunque es un tema que excede los objetivos del presente trabajo- dos datos que brinda Battaglia: su militancia política y la calificación de los crímenes como genocidio.

25 A propósito de la carátula de los crímenes perpetrados: "La apelación a la figura crímenes de lesa humanidad también ocupó un lugar central en el relato público que presentaban algunos de los miembros de los organismos de derechos humanos que integraban la CVJ [Comisión de Verdad y Justicia] para explicar lo acontecido, aunque incluyendo algunos cambios: la idea de crímenes de lesa humanidad era combinada con una apelación al derecho de la verdad como aspecto humanitario en el marco de un doble derecho de los familiares y de la sociedad, pero también era utilizada como un modo de apelar a la restitución de una situación de igualdad 
uso militante correría el riesgo de restringir su alcance universal $y$, en consecuencia, de aparecer como ilegítimo" (Pollak 2006: 84). Ahora, en el año 2001 y con un panorama político bien diferente, el testimonio refiere y reivindica su militancia. Una de las abogadas, quien alude a la militancia, además de indagar en la profesión de Battaglia, dice lo siguiente: "Señor Battaglia, volviendo al momento de la detención suya el 24 de marzo del '76, ¿usted nos puede referir-además de su militancia política que era por todos conocida- desde el punto de vista profesional, como abogado, cómo estaban orientadas su carrera, su profesión, de la rama del Derecho?" (Audiencia, 24). Esto último tampoco hubiera sido posible en el año '85, en tanto que la sola exposición de una ideología definida como la de Battaglia habría sido motivo para encuadrarlo políticamente, con los riesgos que ello implicaba en una democracia débil y plausible de ser nuevamente derrocada por los militares.

La transición hacia la democracia es otra de las etapas evocadas en el testimonio, remembranza que se hace, precisamente, por medio de la mención de una de las formas de búsqueda de la verdad y la justicia, como lo fueron los reconocimientos hechos por parte de la Comisión Nacional sobre la Desaparición de Personas (CONADEP), comisión asesora creada por el presidente Raúl Alfonsín (su

\footnotetext{
jurídica mediante la exigencia de que la justicia argentina 'se ponga a tono con lo que acontece en otros lugares del mundo donde se está planteando la inconstitucionalidad de las leyes de impunidad, de punto final, obediencia debida y el decreto de indulto' [palabras de Ramiro Fresneda]. No todos los organismos enfatizaban la figura de crímenes de lesa humanidad. La APDH-MdP [Mar del Plata], la AEDD-MdP e HIJOS preferían referirse a los crímenes como genocidio. Para los integrantes de estas organizaciones explicar lo acontecido como genocidio permitía una definición del proyecto político que estaba por detrás del accionar del terrorismo de Estado" (Andriotti Romanin 2013b: 115).
}

mandato abarcó de 1983 a 1989) el 15 de diciembre de 1983 con el fin de investigar las violaciones a los derechos humanos, a días de haber asumido y, por lo tanto, a días de finalizada la dictadura. Battaglia alude al carácter inestable del gobierno democrático que imperaba por entonces y a la amenaza y el temor frente a la inminencia de un nuevo golpe al gobierno constitucional. Expresa todo esto recurriendo a la descripción de la actitud de los militares ante los reconocimientos de la CONADEP, los cuales fueron hechos "con la presencia de los oficiales y con todo su aspecto de 'mirá lo que va a pasar si sucede otra vez', una actitud provocativa de todos, en lugar de ser una actitud de descubrir qué era lo que había sucedido porque en definitiva ellos a lo mejor ni habían estado en ese lugar, pero había una tendencia-que creo que sigue todavía- de esconder y de ser cómplice de esa situación" (Audiencia, 17). Como señala Emilio Crenzel:

\footnotetext{
Frente a la presencia de la Comisión, el personal militar o policial osciló entre intentar impedir la inspección, negar todo saber sobre la existencia de la infraestructura material denunciada o retacear información sobre su personal en los tiempos en que oficiaban como cárceles ilegales. En otras ocasiones, los testigos fueron amenazados o acosados in situ durante los propios reconocimientos (Crenzel 2008: 77).
}

El testimonio postula la sola presencia de los miembros de las Fuerzas Armadas como forma y mecanismo de amenaza, un modo más sutil de amedrentamiento que la intimidación directa, pero no por ello menos temible. Es innegable que el miedo y el terror trascendieron los límites temporales de los denominados años de plomo, extendiéndose en la postdictadura.

Las imágenes que se actualizan sobre la justicia pertenecen también a la temporalidad del pasado dictatorial. En esta etapa, los derechos 
constitucionales fueron suspendidos y la administración de justicia quedó supeditada a la voluntad y arbitrio de los militares. Muchas de las instituciones vinculadas con lo jurídico y los espacios físicos concretos en los que ella actuaba se convirtieron en territorios minados por las directivas y por parte del accionar de las fuerzas represivas. Como es sabido, en aquella época, recurrir a la justicia por motivos políticos se tornaba incluso peligroso para los abogados defensores, como lo manifiesta Battaglia a propósito de colegas y de él mismo. Así lo exhibe: "Nosotros cuando teníamos que ir a la Fiscalía Federal por detenidos de esa época, que ir a ver detenidos, interesarse en ese tiempo era también asimilarlo al detenido con el defensor, diría que hasta era peligroso porque más de una vez hemos visto armas arriba del escritorio, en la fiscalía" (Audiencia, 30). Más tarde, agrega:

Ir solamente al Juzgado Federal ya era, en esa época, un lugar donde a uno lo atendían desconsideradamente. Los propios empleados del Juzgado Federal, cuando íbamos por los presos era una cosa, que le negaban los expedientes, impedían que habláramos con los jueces. Tratábamos de descubrir realmente y nunca podíamos obtener ni en la fiscalía ni en el juzgado noticias verdaderas de los expedientes que estaban tramitando de detenidos que ya estaban desaparecidos (Audiencia, 30).

Se trataba de una justicia intencionadamente conculcada por la imposición del miedo. Es por ello que durante el gobierno de facto y ante la falta de respuestas en el ámbito jurídico, los familiares de los secuestrados prefirieron recurrir a organismos de Derechos Humanos, como lo señala Battaglia en su testimonio a partir de la mención del caso de un hombre desaparecido en la provincia de Jujuy (Audiencia, 11). Los Juicios por la Verdad, si bien despojados de alcances en términos de una justicia retributiva en lo inmediato o como finalidad directa, como ya se señaló, implican una contundente apropiación simbólica de ciertas territorialidades de la justicia. El fiscal Félix Crous subraya que en los juicios "se jerarquiza el espacio y el rol de la víctima, que puede brindar su versión pública de la historia en el lugar simbólicamente más importante de los tribunales, donde en la dictadura sólo encontraba puertas cerradas, funcionarios esquivos y estrados vacíos" (Crous citado por Miguel 2006: 27). El aspecto simbólico adquiere peso: “(...) el espacio judicial pasó de ser un 'espacio traumático' a recuperar un lugar representativo como garante de los derechos humanos" (Andriotti Romanin 2013b: 74). Si los procedimientos de la justicia durante la dictadura aparecen representados en la imagen de instituciones inermes frente a los crímenes cometidos, en el presente de los juicios los modos de recurrir a la justica serán diferentes. Se da una clara oposición con las formas de apelación a la justicia durante el gobierno de facto. En consonancia con esto, resulta interesante resaltar la "dimensión ritual" que destaca Mora a propósito de estos juicios (Andriotti Romanin 2013a: 7). Sin dudas, la posibilidad real de recurrir a un poder antes vedado forma parte de tal carácter ritual. Asimismo, podría hablarse de la constitución de un lugar de la memoria, en una torsión del significado que Pierre Nora (2015) atribuye a tal concepto. De este modo, el tribunal se convierte en un lugar de memoria en sentido amplio. Inclusive, en la actualidad durante la cual los genocidas son juzgados penalmente, estos espacios de memoria se llegan a señalizar como tales, a veces de modo efímero. En Mar del Plata, como en otros lugares, se cuelgan en la vereda del Tribunal Oral Federal los famosos pañuelos -símbolo de las Madres de Plaza de Mayo- consignas y banderas que señalizan el sitio como un lugar de memoria: "Aquí se juzgan 
genocidas" es una de las banderas que señalan, indican y territorializan el espacio como lugar de memoria (y justicia) patente. Cuando, luego de que la audiencia tenga lugar, se retiran las banderas, queda latente ese espacio, para los actores sociales comprometidos y también para quienes frecuentan el sitio, como lugar de memoria, verdad y justicia.

Si en la Argentina de mediados de los '90 la justicia respecto de los crímenes perpetrados durante el régimen castrense queda relegada por la impunidad, en el panorama internacional existe otra figuración de ella, por medio de la cual pueden ser juzgados represores en tierras extranjeras. Esta justicia internacional es dimensionada por Battaglia como representación o correlato de una justicia en potencia para el futuro en Argentina:

\begin{abstract}
Entonces yo creo que es un hecho auspicioso y a uno lo hace revivir el hecho de que se empiece a juzgar hechos delictivos, no dentro del territorio donde los han cometido sino en cualquier lugar del mundo, para que no puedan escapar, para que no se puedan ir a otro lado. Pero en este caso de nuestro país, para que no puedan venir a nuestro país. Fíjese, señor Presidente y Excelentísimo Tribunal lo que significa que Cavallo, un torturador reconocido y recontra denunciado, quiera venirse a la República Argentina donde cometió todos los delitos, porque sabe que aquí no lo van a juzgar y eso es la injusticia puesta al servicio de estos torturadores. $Y$ este hecho de que el poder político de Méjico [sic] haya autorizado la extradición de él indique que esto se termina y que ya los torturadores, los que cometan genocidios, que cometan este tipo de cosas, no se van a sentir tan cómodos en cualquier lugar del mundo en el que estén (Audiencia, 36).
\end{abstract}

Se da la convicción de que existirá una justicia en el futuro (tomando como presente el momento del testimonio, esto es, el año 2001) junto con la verdad que, a partir de ellos, pueda ser rescatada tanto de entre los ocultamientos $y$ el silencio de quienes cometieron los crímenes, como del olvido impuesto por los gobiernos hasta ese presente. En esta dirección, Battaglia, al final de su testimonio, postula la verdad a reconstruir como una especie de "memoria ejemplar" (tomamos en préstamo la noción de Tzvetan Todorov). Antes, esboza las causas y motivaciones del último gobierno inconstitucional, encontrando en el plan económico de José Alfredo Martínez de Hoz (bajo un sistema orquestado por Estados Unidos) los motivos de la represión sistemática implementada por el régimen castrense en Argentina. En este sentido, uno de los mecanismos discursivos del testimonio redunda en incluir en su interior zonas y fragmentos de tono y registro histórico. Una cuestión que quizá excede el concepto de verdad postulado por estos juicios, pero que sin duda se relaciona con él. Este recurso se ve a lo largo de la declaración, la cual se constituye en la confluencia de diferentes registros y tonos del lenguaje ${ }^{26}$ y de diversos referentes, aunque, por supuesto, todos nucleados por la cuestión de la dictadura. A lo largo de la declaración, se diagrama un conglomerado de registros discursivos que la convierten en un texto heterogéneo y en el que es evidente que el testimonio puede explayarse en múltiples sentidos, lo que constituye una clara diferencia con las declaraciones en el Juicio a las Juntas en 1985. De hecho, la instancia jurídica del testimonio carga con la función de devolver la voz a aquellos que fueron silenciados durante el régimen de facto. En el caso del testimonio de Battaglia, este gesto y acto de recobrar la voz se reviste de un segundo significado, en cuanto

26 El testimonio de Battaglia está signado por diferentes gradaciones y matices del discurso que van desde la objetividad (sabiendo que la objetividad nunca es total, en ningún discurso; la sola elección del modo y de las estrategias enunciativas del narrar dependen ya del sujeto, por lo que son subjetivas) de ciertos hechos y acontecimientos hasta la subjetividad implícita en sensaciones e impresiones. 
que él expone, si bien en un sentido general, críticas a la dictadura que en aquel momento fueron censuradas y perseguidas, así como manifiesta ciertas convicciones que forman parte de su ideología. En esta dirección, se logra reivindicar su voz no solo en torno a los crímenes que sobre él se perpetraron, sino en cuanto a ideologías que fueron silenciadas en otro momento histórico, más allá de que quien las escucha en el presente esté de acuerdo o no con ellas. Con la posibilidad de estos juicios, emergen sobre la superficie "memorias subterráneas" -empleando el concepto de Michael Pollak- que venían ya descubriéndose luego de la finalización de la dictadura, pero que así y todo continúan, para el año 2001, sobre cierto margen de los discursos oficiales. De este modo, Battaglia se refiere a determinadas consecuencias del neoliberalismo que dejó como nefasto legado el último gobierno de facto y al panorama de la postdictadura, pero con la esperanza ("la utopía") de que se reconstruya la verdad en pos de la justicia:

Eso es lo que permitió lo que hoy estamos sufriendo. Pero como decía en otra oportunidad, estas alegrías que nos da y aparece como que la utopía de uno va a ser realidad, también las sentí en el Foro Social Mundial que se hizo en Porto Alegre hace pocos días y digamos, contrarresta y nos abre un camino y nos indica que hay una luz al final, que este proceso de globalización, de destrucción de nuestro mundo, del aire, el agua, de los bosques, todo esto que la globalización ha traído, de la desocupación, de los excluidos, indica este foro donde asistieron más de diez mil personas, que otro mundo es posible como lo indica la propia consigna con la que se reunió. Yo creo que hay otro mundo, que es posible otro mundo y que es necesario otro mundo, para eso he sido abogado y político a la vez, si quieren definirme rápidamente, con la idea de cambios que la humanidad sea otra, no ésta, la de los desocupados, la de los hambrientos, la de los que tienen que ir a los supermercados a exigir comida o los que tienen que paralizar las rutas para que haya comida o para que se haga un camino como lo hizo el intendente de Pinamar o de Madariaga (Audiencia, 36).
Subyace a este fragmento la pregunta de qué democracia es posible si no hay justicia por los hechos vividos durante la dictadura. A continuación, finaliza esta especie de epílogo de su testimonio de la siguiente manera: "De eso me siento con ganas todavía para ese logro y estas utopías y espero que esto que hemos comentado sirva para descubrir la verdad $y$ que la gente tenga los antecedentes de lo que está sucediendo. Nada más" (Audiencia, 36). (Destacado nuestro). Es en este sentido que el testimonio presenta el "des-cubrimiento" de la verdad a modo de memoria ejemplar, lo que se materializa discursivamente en la expresión destacada en el fragmento. Asimismo, dicha frase podría bien aludir al hecho de que los Juicios por la Verdad presentes tengan efectos futuros en cuanto a justicia retributiva se refiere. Se trataría en última instancia, de que (esa verdad de) lo sucedido contenga una intención ejemplarizante y en este aspecto viene a añadirse, de forma solapada, la búsqueda de una justicia y un castigo ejemplar en el futuro. Se trataría de "Juicios por la Verdad y para la justicia".

\section{Consideraciones finales}

Los Juicios por la Verdad se constituyeron, en Mar del Plata así como en las otras ciudades de Argentina en las que se llevaron a cabo, en espacios jurídicos de resistencia frente a un Poder Ejecutivo y Legislativo ( $y$ aun parte del Judicial) que hacían caso omiso a todo intento de revisión del pasado reciente. El silencio sobre los hechos y crímenes perpetrados por los represores fue impuesto desde los mismos inicios de la dictadura y perpetuado tanto en el pacto de silencio de los militares, así como en los sucesivos gobiernos democráticos -con 
la excepción del hito del Juicio a las Juntas en 1985 y lo anterior a él desde la vuelta de la democracia- hasta el año 2003. Todo ello convierte al testimonio de estas instancias jurídicas en un espacio de resistencia, en cuanto que se da en un contexto en el que desde la esfera oficial se apela tanto a la impunidad como al olvido de lo sucedido.

En el marco de silencio y en una emergencia de la memoria histórica a nivel local e internacional, surgen estos Juicios por la Verdad. En ellos, el testimonio de quienes fueron víctimas directas y a su vez testigos de otros crímenes significa una instancia no solo necesaria sino también fundamental. El otorgamiento de voz a quienes fueran por tiempo silenciados significa ya la restitución de un derecho, con lo que se delinea una dimensión simbólica de la justicia.

Al analizar, a modo de estudio de caso un testimonio puntual es posible notar que el relato testimonial adquiere otros matices discursivos además de la reconstrucción de la verdad. La declaración se presenta como espacio textual desde el cual se reflexiona sobre dos ideas centrales en estos juicios: la de verdad, patente, y la de justicia, latente. Es en este sentido que el testimonio de Battaglia se construye como metatexto, en tanto que se vuelve sobre sí mismo para formular reflexiones acerca de la justicia.

La declaración analizada se refiere a la justicia del pasado dictatorial en calidad de justicia improcedente y como sitio minado por el régimen de facto. Los espacios físicos de las instituciones judiciales se presentan ellos mismos como embajadores del terror que instauran los represores. Es por ello que la instancia presente del juicio se reviste de un carácter simbólico, pues abre un espacio a sujetos que vehiculizan discursos e ideologías silenciados y a los que antes se les había vedado tal lugar. Posteriormente, aparece la imagen de una verdad que busca justicia en medio de una democracia endeble, que hace pensar y actuar conforme a los riesgos que ello conlleva. Se trata de la justicia en la inmediata postdictadura, de los reconocimientos de la CONADEP y del Juicio a las Juntas. Finalmente, se figura la idea de una justicia no en acto sino en potencia, una posibilidad de justicia a futuro, que viene a completar la finalidad de los Juicios por la Verdad: la idea de justicia no deja de estar presente aunque sea en forma solapada. Acaso para el momento fuera solamente una esperanza, pero lo cierto es que el declarante manifiesta su convicción acerca del juzgamiento futuro de los represores en correspondencia con la idea de justicia que subyace a estos juicios. Ésta y otras ideas sobre la justicia son tematizadas, referidas o tan solo aludidas en la declaración de Battaglia, generando representaciones al interior del testimonio que exceden y a la vez se corresponden con la idea de justicia implícita en los Juicios por la Verdad.

De esta manera, el testimonio se convierte en un espacio en el que, tanto externa como internamente, se reconstruyen las ideas fundamentales del Juicio. Hacia el exterior del discurso, el testimonio en general (el de Battaglia así como las declaraciones de otros testigos) constituye la forma de reconstrucción de la verdad sobre unos hechos que han sido silenciados y que se encuentran disgregados. En el interior del testimonio de Battaglia, se formulan elucubraciones acerca de la concepción de justicia que él posee, concordante, en lo general, con la definición de tal concepto como fundante de los Juicios por la Verdad. La visión que se 
tiene sobre la justicia surge no solo del espacio del testimonio como discurso visto desde fuera, como instancia que forma parte de un juicio, sino en el propio interior, desde las mismas palabras de quien enuncia. El relato testimonial ocupa un espacio de resistencia y es sinónimo de lo reparador en un doble sentido: por un lado, permite al sobreviviente relatar los hechos de los que fue víctima. En este sentido, gracias a la modalidad de los Juicios por la Verdad, el sobreviviente encuentra un interlocutor válido dispuesto a escuchar el relato del horror; en una segunda instancia, quien testimonia encuentra un sitio en el cual formular sus ideas acerca de la justicia sobre tales hechos. Es decir, no solamente puede elaborar un relato de lo sucedido, sino además expresar sus opiniones acerca del tratamiento que se le ha dado a esos acontecimientos en el pasado y en el presente, así como de los posibles cauces de acción para el futuro. A la narración de los hechos y de lo que tiene que ver con el plano de lo factual viene a superponerse la reflexión sobre las ideas que dan fundamento al juicio.

\section{Bibliografía}

Andriotti Romanin, E. 2010. Las luchas por el sentido del pasado dictatorial en la ciudad feliz. Memoria(s) y política(s) en el Juicio por la Verdad de Mar del Plata. Instituto de Desarrollo Económico y Social-Universidad Nacional de General Sarmiento. Tesis de Doctorado. Disponible en: https://www.ungs.edu.ar/wpcontent/uploads/2012/06/Tesis_Andriotti_Romanin.pdf

2013a. "Decir la verdad, hacer justicia. Los Juicios por la Verdad en Argentina". European Review of Latin American and Caribbean Studies, Center for Latin American Research and Documentation, University of Amsterdam. Netherlands. $\mathrm{N}^{\circ} 91$, Abril-Julio: 24-43.

2013b. Memorias en conflicto: El movimiento de Derechos Humanos y la construcción del Juicio por la Verdad de Mar del Plata. Mar del Plata: Eudem.

Asociación Madres de Plaza de Mayo. 1995. Historia de las Madres de Plaza de Mayo. Buenos Aires: La Página S.A.

Badenes, D. y Miguel, L. 2007. "Ni héroes ni traidores". Revista Puentes. La Plata: Año VII, N²1: 6-15.

Celesia, F. y P. Waiseberg 2016: La noche de las corbatas. Cuando la dictadura silenció a los abogados de los trabajadores. Buenos Aires: Aguilar.

CONADEP. 1984. Nunca más. Informe de la comisión Nacional sobre la desaparición de personas. Buenos Aires: Eudeba.

Crenzel, E. 2008. La historia política del Nunca más. La memoria de las desapariciones en la Argentina. Buenos Aires: Siglo veintiuno.

2010. "Introducción" y "La víctima inocente: de la lucha antidictatorial al relato del Nunca más". Los desaparecidos en la Argentina. Memorias, representaciones e ideas (1983-2008). Crenzel, E. (coord.). Buenos Aires: Biblos. 11-23 y 65-83.

Duhalde, E., Rousseaux, F., Bosch, M., Said, J. y Vásquez, G. (2009). Acompañamiento a testigos en los juicios contra el terrorismo de Estado. Primeras experiencias. Buenos Aires: Ministerio de Justicia, Seguridad y Derechos Humanos de la Nación. Secretaría de Derechos Humanos.

Filippini, L. 2011. "La persecución penal en la búsqueda de justicia”. CELS. Hacer justicia. Buenos Aires: Siglo veintiuno. 19-47.

Huyssen, A. 2001. En busca del futuro perdido. Cultura y memoria en tiempos de globalización. Buenos Aires: Fondo de Cultura Económica.

Jelin, E. (1995). "La política de la memoria. El movimiento de derechos humanos y la construcción democrática en Argentina". Juicios, castigos y memorias. Derechos humanos y justicia en la política argentina. Acuña, C. \& otros, Buenos Aires: Nueva Visión. 2004. "Minorías y luchas políticas". Revista Oficios terrestres. Año X. Número 15/16. Comunicación y memoria. Estrategias de conocimientos y usos políticos: 10-21.

2010. “¿Víctimas, familiares o ciudadanos/as? Las luchas por la legitimidad de la palabra". Los desaparecidos en la Argentina. Memorias, representaciones e ideas (1983-2008). Crenzel, E. (coord.). Buenos Aires: Biblos. 227-249.

LaCapra, D. 2006. Historia en tránsito. Experiencia, identidad, teoría crítica. Buenos Aires: Fondo de Cultura Económica.

Levi, P. 2006. La tregua. Barcelona: Quinteto.

Lvovich, D. y Bisquert, J. 2008. La cambiante memoria de la dictadura. Discursos públicos, movimientos sociales y legitimidad democrática. Los Polvorines: Universidad Nacional de General Sarmiento; Buenos Aires: Biblioteca Nacional.

Memoria Abierta. 2010. Abogados, derecho y política. Buenos Aires: Memoria Abierta: 124- 134.

Miquel, L. 2006. "Juicios por la verdad. Grietas en la impunidad”. Revista Puentes. La Plata. Año VI, No 17. Abril: 25-35.

Nora, P. 2008. Pierre Nora en Les lieux de mémoire. Montevideo: Trilce. 
Pollak, M. 2006. Memoria, olvido, silencio. La producción social de identidades frente a situaciones límite. La Plata: Al margen.

Ricoeur, P. 2003. La memoria, la historia, el olvido. Madrid: Trotta.

Rousseaux, F. 2009. "Memoria y verdad. Los juicios como rito restitutivo". Duhalde, E. \& otros, Acompañamiento a testigos en los juicios contra el terrorismo de Estado. Primeras experiencias (pp. 28-38). Buenos Aires: Ministerio de Justicia, Seguridad y Derechos Humanos de la Nación. Secretaría de Derechos Humanos.

Sarlo, B. 1987. "Política, ideología y figuración literaria". Ficción y política. La narrativa argentina durante el proceso militar. Balderston et. al. Buenos Aires-Madrid: Alianza. 30-59.

Schapiro, H. 2002. "Surgimiento de los 'Juicios por la Verdad'”. El vuelo de Ícaro. (2-3): 359-401.

Semprún, J. 2004. La escritura o la vida. Buenos Aires: Tusquets.

Teitel, R. G. 2003. "Genealogía de la justicia transicional". Traducción del Centro de Derechos Humanos de la Facultad de Derecho, Universidad de Chile. Título original: "Transitional justice genealogy". Harward Human Rigths Journal, Cambridge MA: Cambridge. (16) spring: 69-94. (Versión electrónica en español: 1-27). Disponible en https://imas2010.files.wordpress. com/2010/07/teitel_genealogia.pdf (consultado en noviembre de 2016)

Todorov, T. 2008. Los abusos de la memoria. Barcelona: Paidós.

Traverso, E. 2011. El pasado, instrucciones de uso. Buenos Aires: Prometeo Libros.

Varsky, C. 2011. "El testimonio como prueba en procesos penales por delitos de lesa humanidad". Hacer Justicia. Nuevos debates sobre el juzgamiento de crímenes de lesa humanidad en Argentina. CELS. Buenos Aires: Siglo Veintiuno editores. 49-77.

Verbitsky, H. 2004. El vuelo. Buenos Aires: Sudamericana.

Vezzetti, H. 2002. Pasado y presente. Guerra, dictadura y sociedad en la Argentina. Buenos Aires: Siglo veintiuno. 2009. Sobre la violencia revolucionaria. Memorias y olvidos. Buenos Aires: Siglo veintiuno.

Vinyes, R. (ed.) 2009. El estado y la memoria. Buenos Aires: Del nuevo extremo-RBA (España).

Yerushalmi, Y. et. al. 1989. Usos del olvido. Buenos Aires: Nueva Visión.

Žižek, S. 2013. Sobre la violencia. Seis reflexiones marginales. Buenos Aires: Paidós. Traducción de Antonio José Antón Fernández. 